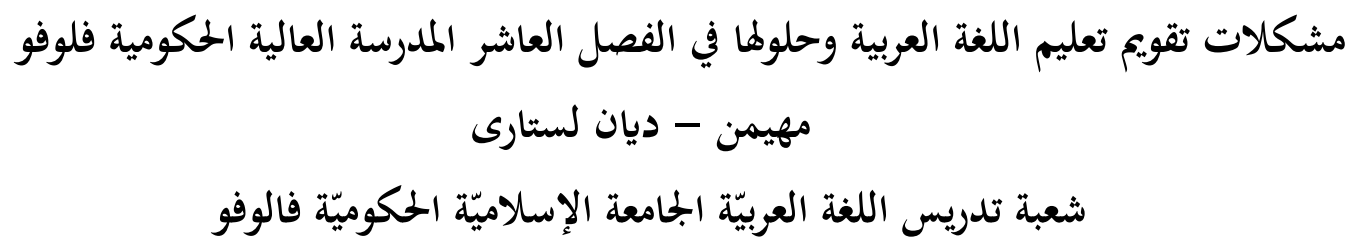

E-mail: elmahady79@yahoo.com

\begin{abstract}
Abstrak
Penelitian ini merupakan penelitian kualitatif yang dilakukan dalam bentuk deskriptif. Metode pengumpulan data dalam penelitian ini dilakukan melalui wawancara, observasi, dan dokumentasi. Sedangakan metode analisis datanya adalah deskriptif, yang menggambarkan dan menganalisis semua hal yang menjadi fokus penelitian ini. Hasil penelitian adalah (1) model evaluasi yang digunakan dalam pembelajaran bahasa Arab adalah evaluasi dasar kelas secara bekelanjutan. (2) Bentuk evaluasi yang dipergunakan oleh guru bahasa Arab adalah penggunaan dua bentuk tes saja dari jenis-jenis evaluasi. (3) Hambatan yang dihadapi oleh guru adalah masalah teknis pada uji ambang batas dari nilai 75 standar utuk dijadikan sempurna atau lengkap yang terasa berat bagi kebanyakan pengajar. Solusi yang ditawarkan adalah menggunakan sistem penjadwalan sehingga waktu terdengar cukup untuk menguji peserta didik dan memberikan tugas tambahan bagi mereka yang memiliki program remedial karena mereka belum mencapai minimum.
\end{abstract}

Kata kunci: Problematika pembelajaran bahasa Arab

$$
\text { تجبيد البحث }
$$

هذ البحث هو البحث الكيفيّ الذي بحث في شكل وصفي وطريقة جمع البيانات في هذا البحث من خلال المقابلات والملاحظة، والوثائق. اساليب تحليل البيانات المستخدمة وصفية، التي تصف وتحلل كل الأشياء التي هي محور هذا البحث. من نتائج البحث هى (1) نموذج الثقويم المستخدمة في تعليم اللغة العربية هي التقويم على أساس الفصل المستمرة. (2) نموذج التقويم المستخدم من قبل معلمي اللغة العربية هو استخدام اثنين فتط من نموذج تقويم استمارة توييم الاختبارات. (3) العوائق التي تواجه المعلمين هي المشاكل التقنية بشأن توقية الاختبار فضلا عن تحقية الحد الأدلي من قيمة 75 معايير لتأكد من اكتمالها أن يشعر الثقيلة لمعظم المتعليمين. تقدم الحلول باستخدام نظام جدولة كتلة بجيث يسمع الوقت لاختبار ما يكفي للمتعلمين لا ستكمال وتوفير مهام إضافية للطلاب الذين لديهم لمنابعة البرنامج العلاجي لأنما لم تصل بعد إل تتحقيق الحد الأدلى. كلمات رئيسية: مشكلات تقويم اللغة العربية، المدرسة العالية 
التعليم هو واحد جهدا واعيا لتحقيق الإمكانات الموجودة. مع التعليم كونه رجل نبيل

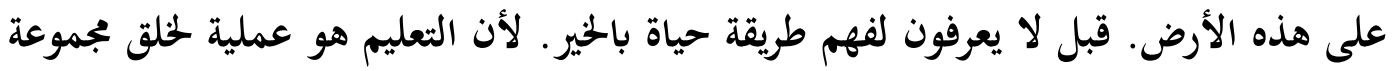
متنوعة من حسن السير والسلوك. كما هو الحال في القانون العام 2003 رقم 20 لنظام1

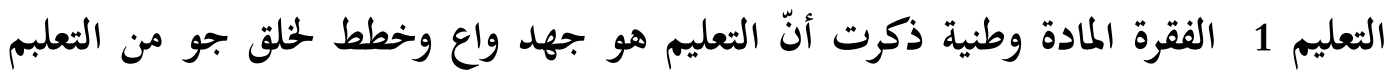

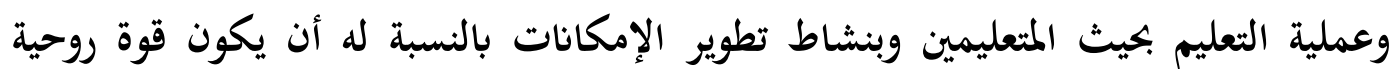

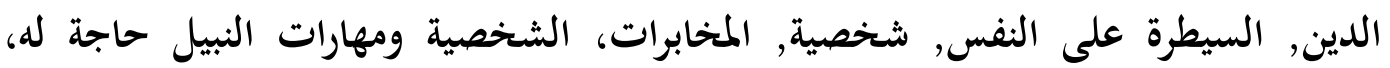
والجنتمع والأمة والدولة. 1

التعليم هو قضية مهمة لكل بناء الأمة. جهود التحسين في مجال التعليم أمر لا بد ولد منه لترى دائما ان يمكن لأمة أن تتقدم وتتطور مع التقدم في العلوم والتكنولوجيا. وتشمل بعض الجهود تنفيذها تحسين المناهج الدراسية، وتعزيز المناهج الدراسية، وتحسين كفاءة المعلمين من خلال تحسين دورات تطوير المرافق التعليمية وغيرها. ويتم ذلك لتحسين نوعية التعليم وخلق اندونيسيا الإنسان تماما.

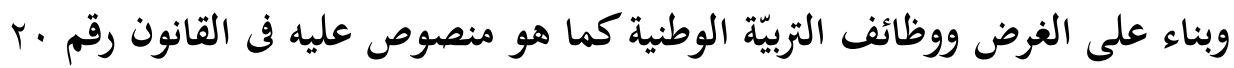
سنة r..r (التربيّة الوطنيّة مادة ץ). يخدم التربية الوطنية لتطوير القدرة على تكوين شخصية

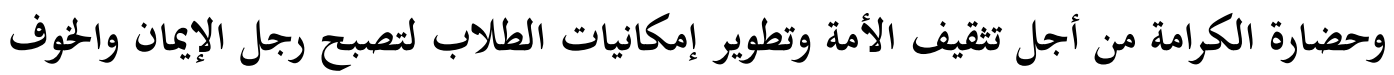
من الله سبحانه وتعالى عز وجلئ، الطابع النبيل، وصحية، والمعرفة، المهرة، والإبداعية، ومستقل ويصبحوا مواطنين في دولة ديمقراطية ومسؤولة. 2

لتحقيق المدف المنشود ثم في المؤسسات التعليمية الرسمية، وهي الممارس. يتم تحديد

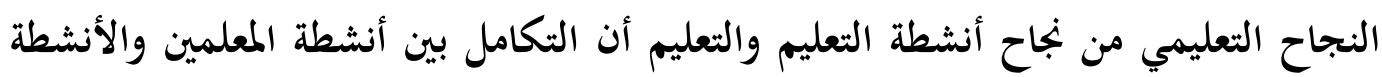
الطلابية. كيف يتعلبم الطلاب كيفية تحديد بكثير تعليم المعلمين .محاولة واحدة لتحسين التئين

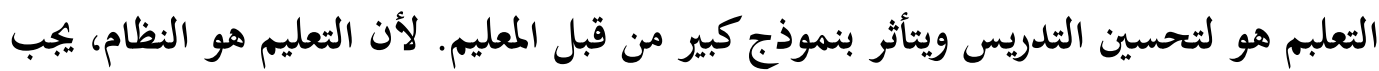

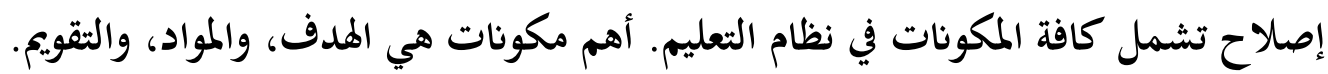

${ }^{1}$ Muhibbin Syah, Psikologi Pendidikan dalam Pendekatan Baru, (Cet.XIII; Bandung: Remaja Rosdakarya, 2007), h. 1. h. 4 .

${ }^{2}$ E. Mulyasa, Standar Kompotensi Sertifikasi Guru, (Bandung: Remaja Rosdakarya 2007), 
لتحسين نوعية وكمية أنشطة التعليم والتعلبم التي يقوم بها المعلمين, ثم ينبغي أن

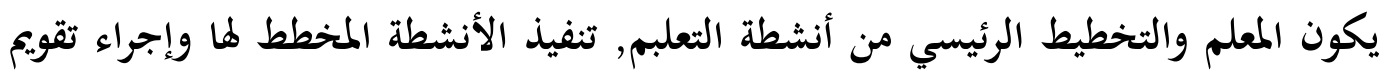
لنتائج عملية التعلبم.

قدرة المعلمين في تخطيط وتنفيذ عملية التعلبم هي عامل رئيسي في تحقيق هدف التدريس. المهارات اللازمة لتخطيط وتنفيذ عملية التعليم والتعلبم هو الثيء الذي هو علاقة

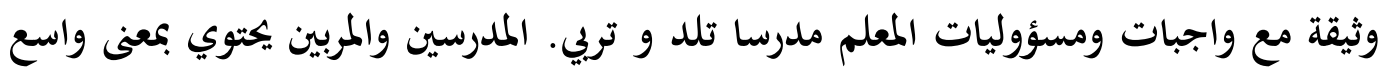
جدا، لا تقتصر على توفير المواد التعليمية ولكن الوصول إلى الأخلاق وجماليات السلوك في الئي

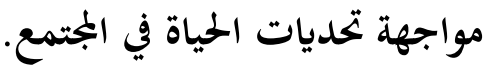
الدراسات النظرية

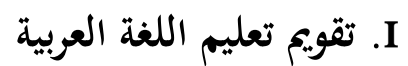

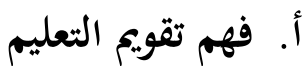

حرفيا كلمة مشتقة من اللغة الإنجليزية هي تقويم الذي يعني الاندونيسية التقويم .في جوهرها، والتقويم هو عملية منهجية ومستمرة لتحديد نوعية )قيمة ومعنى (من شيء على

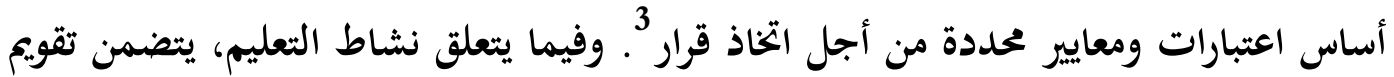

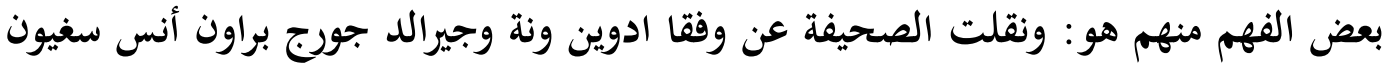

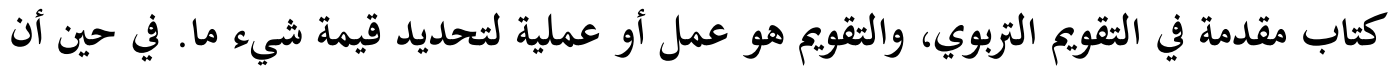

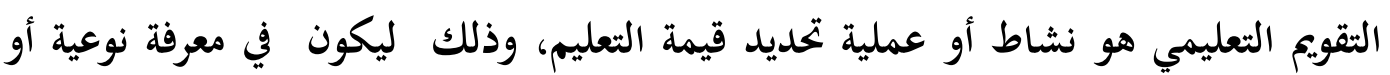
نتائج.

من أجل فهم أفضل ما هو المقصود من التقويم، ثم هناك على الأقل ثلاثة الجوانب

$$
\text { التي ينبغي النظر فيها: }
$$

1. ) التقويم هو عملية منهجية، وهذا يعني أن التقويم) في التعليم (هو النشاط الذي خططت ونفذت على نحو مستمر. التقويم هو ليس مجرد نشاط أو تغطية نهاية الدرس، بل هو النشاط الذي نفذ في البداية، أثناء عملية التعليم تجري، وفي غهاية الدرس.

${ }^{3}$ Zaenal Arifin, Evaluasi Pembelajaran, (Bandung; Remaja Rosdakarya, 2009), h. 5.

${ }^{4}$ Anas Sudijono, Pengantar Evaluasi Pendidikan, (Cet VII Jakarta: Raja Grafindo Persada 2009), h. 1-2. 
2. ) كل نشاط يتطلب تقويم مجموعة متنوعة من المعلومات أو البيانات المتعلقة الكائن التي

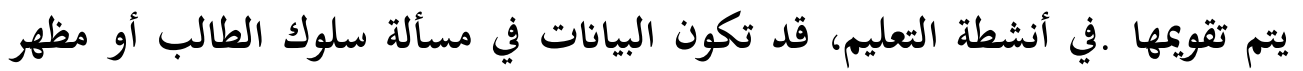

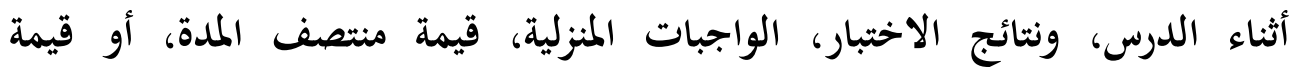

$$
\text { امتحانات الفصل الدراسي، وهلم جرا. }
$$

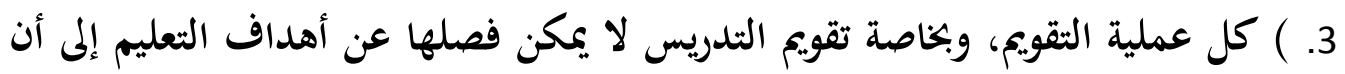

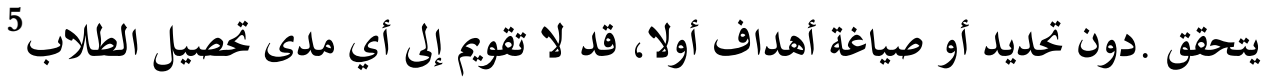

ب. الغرض من وظيفة التقويم

بشكل عام، فإن الغرض من التقويم في مجال التعليم هناك نوعان وهما:

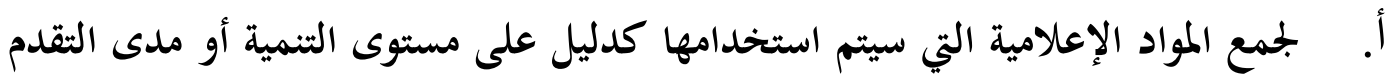

الذي يعيشه المعلمين كما أفما تتبع عملية التعليم في فترة معينة من الزمن.

ب. لتحديد مدى فعالية أساليب التدريس التي استخدمت في عملية التعليم.

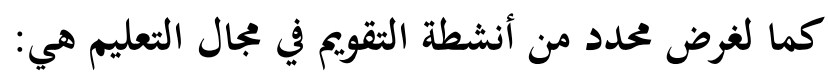

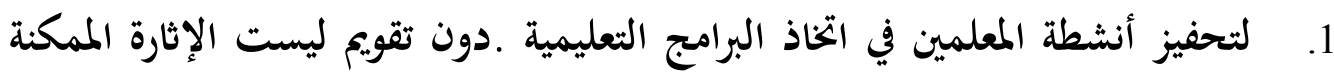

$$
\text { أو تحفيز المعلمين على الذات لتحسين وتعزيز أداء كل منها. }
$$

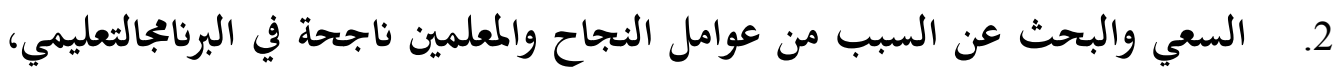

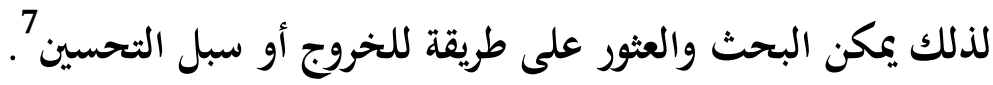

$$
\text { ج. مبادئ التقويم }
$$

مبادئ نتائج التقويم والتعليم هي لقياس نتائج التعليم التي تم تعريفها بوضوح وفقا

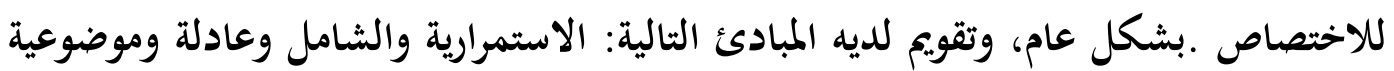
وجمعيةتعاونية وعملي.

المبادئ والعمليات مخرجات التعليم التقويم هو قياس نتائج التعليم التي تم تعريفها بوضوح وفقا للاختصاص .قياس سلوك عينات تمثيلية من نتائج التعليم والمواد التعليمية.

${ }^{5}$ Ngalim Purwanto, Prinsip-Prinsip dan Teknik Evaluasi Pengajaran, (Bandung: Remaja Rosdakarya, 2006), h. 3.

${ }^{6}$ Anas sudijono, op. cit., h. 1.

${ }^{7}$ Ibid, h. 16.

${ }^{8}$ As'Aril Muhajir, Ilmu Pendidikan Perpektif Kontekstual, (Cet, 1; Jogjalarta: Ar-Ruzz Media, 2011), h. 29 
د. أنواع تقويم التعليم

تقويم نتائج التعليم ليست سوى جزء من تقويم التعليم ـكبرنامج، وينقسم تقويم التعليم

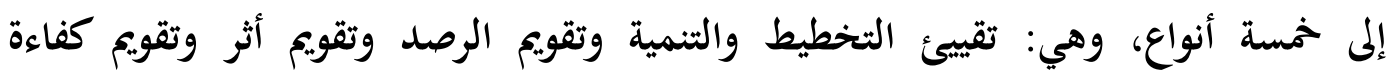

والاقتصادية وتقويم برنامج شامل. 9 II

أ. مشكلات تقويم تعليم اللغة العربية

تعليم اللغة العربية في المؤسسات التعليمية هي عملية التعليم حتى يتمكن الطلاب

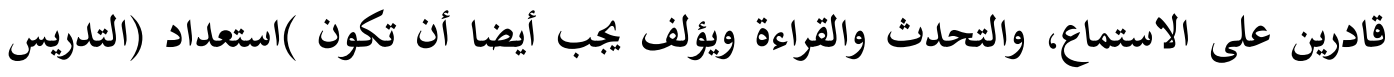

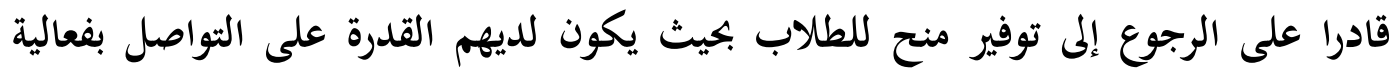

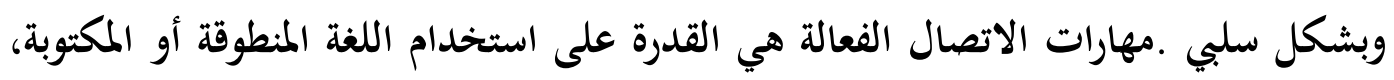
في حين أن مهارات التواصل السلبي هو القدرة على معرفة اللغة العربية قراءة والكلام للآخرين.

لطباعة المثل العليا للطلاب التسجيل أو المعلمين مع هذه القدرات، ويطلب من

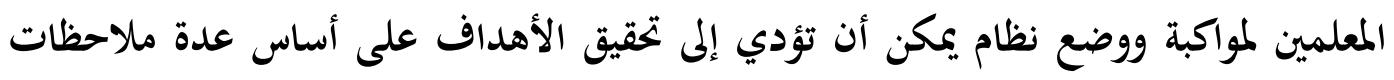

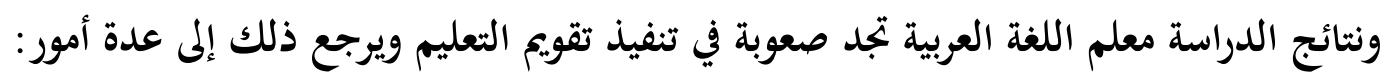

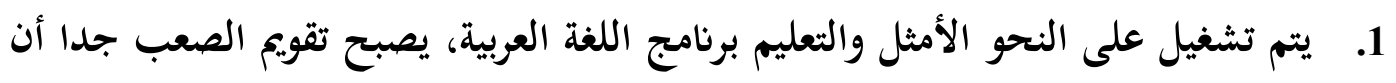

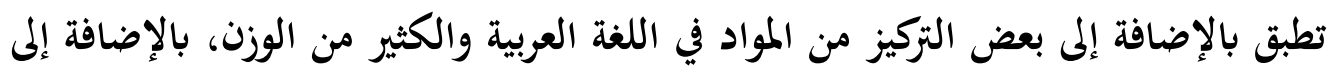

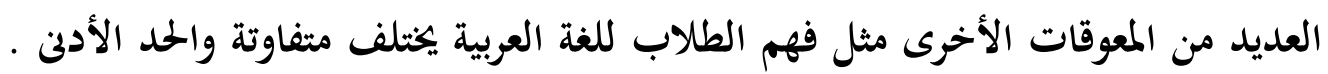

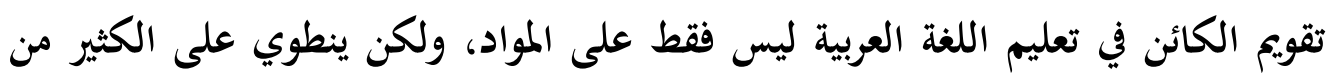

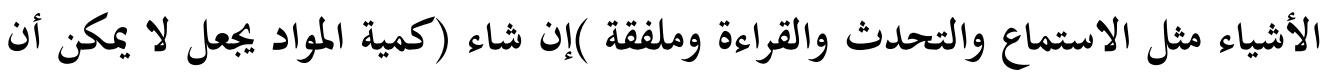
يتم تسليم بعض المواد على النحو الأمثل.

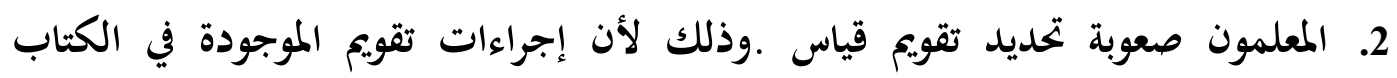
المدرسي تبدو الجوانب المعيارية جدا في نتيجة التقويم في تعليم اللغة العربية أكثر تركيزا

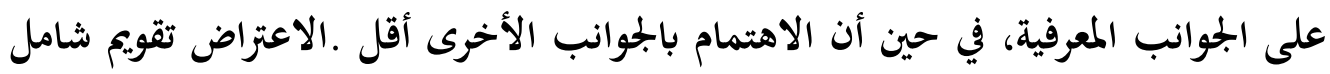
أقل، المزيد من المعلمين لتقويم شكل الاختبار النهائي.

${ }^{9}$ Zaenal Arifin, op. cit., h. 33. 
3. المعلم صعوبة اللغة العربية في تحديد المعايير والمعايير القياسية في الغالب مدرس لغة عربية فقط لا يقيس على أساس النتائج بناء على تلك العمليات .المعلمين يفضلون ملفيد مقارنة

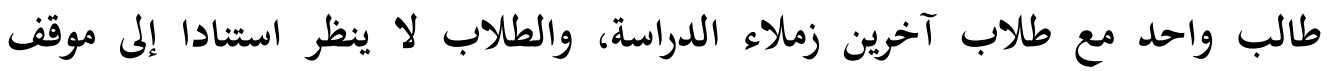

$$
\text { ب. أهمية تقويم التعليم هي: } 10
$$

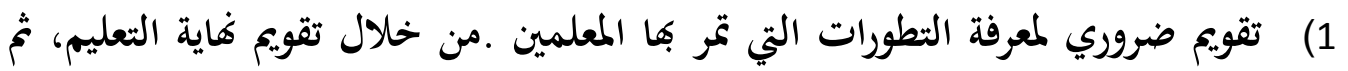

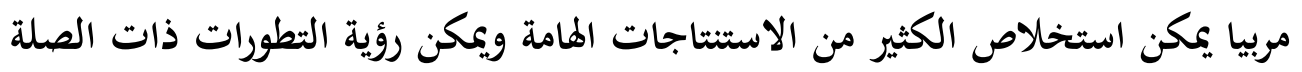
في المقام الأول من تطوير المعلمين.

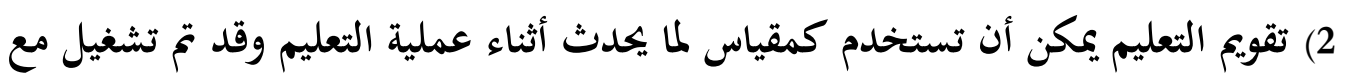
الحد الأقصى أو لا، وسواء المكونات ذات الصلة وكذلك المعلمين والمعلمين، والمواد التعليمية كانت قادرة على دعم عملية التعليم على أكمل وجه. 3) تخطط التعليم في المستقبل هي واحدة من المهام الرئيسية للعقد تقويم التعليم، ومعرفة دهيم

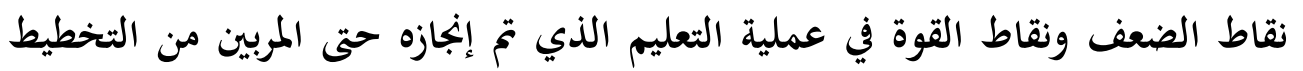
التبويين الخاص بك على التعليم بشكل أفضل هذه الأساليب والاستراتيجيات التعليمية.11. ج. تقنيات تقويم تعليم اللغة العربية

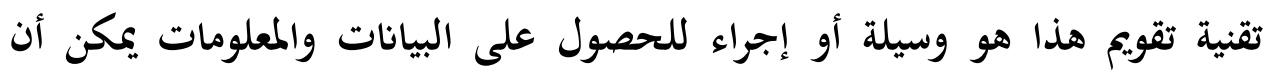

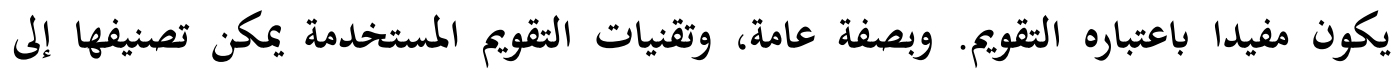

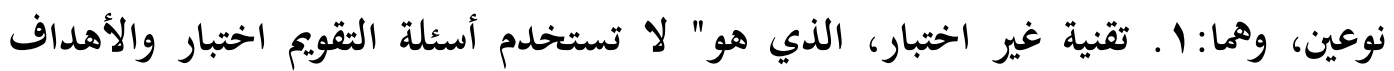

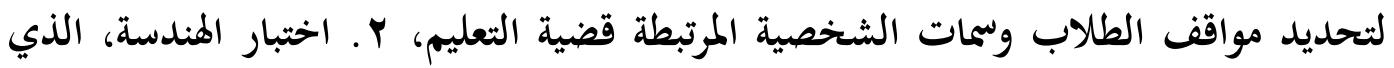

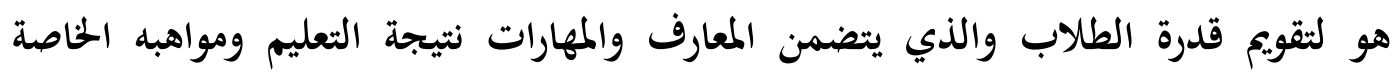
والمخابرات. أ. الاختبارات الميكانيكية

\footnotetext{
${ }^{10}$ Fathul Mujib, Rekontruksi Pendidikan Bahasa Arab dari Pendekatan Konvensional ke Integrative Humanis, (Yogyakarta: Bintang: Pustaka Abadi 2010), h. 175.

${ }^{11}$ Seputar pendidikan 003.blogspot.com/2010/06/Pentingnya Evaluasi Pembelajaran.html 09 September 2014.
} 
من حيث فائدتا لقياس الطلاب سيتم تقسيمها إلى ثلاثة أنواع من الاختبارات، وهي: الاختبارات التشخيصية والاختبارات التكوينية والاختبارات تلخيصي.

ب. تقنية غير اختبار. 1. - المراقبة (مراقبة) 2. مقابلة (مقابلة)

هناك نوعان من المقابلات التي يمكن استخدامها كأداة التقويم، وهي: مفابل أ. مقابلة تسترشد

ب. ل لا يهتدون مقابلات أو مقابلة الجمانية

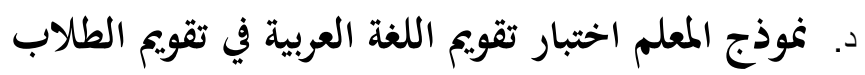

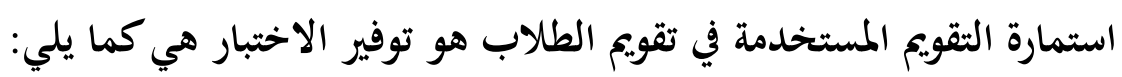

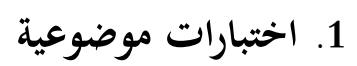

نموذج اختبار تحتوي على المشاركين الإجابات المتتملة يمكن اختبار كامل أجرى

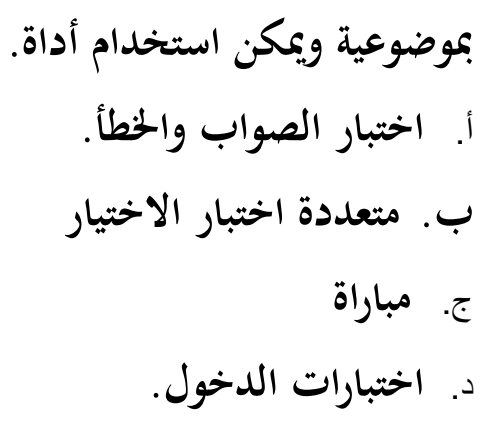

2. اختبارات ذاتية (وصف الاختبارات أو مقال)

وتجرى الاختبارات من خلال عقد سؤال و جواب مع استخدام اللغة المنطوقة مباشرة

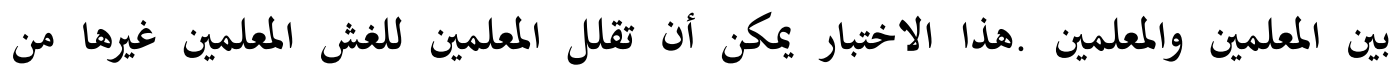
الإجابات، لكنه يأخذ وقتا أطول لتنفيذ هذا الاختبار، وينقسم الاختبار إلى قسمين، وهما:

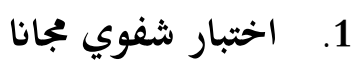
2. 2. اختبار الثفوي تسترشد مناهج البحث أ. منهح و أنواع البحث البحث 
فهج البحث هو العمل الذي قام به الباحث لفهم وتقويم واستكشاف المواد والكائن

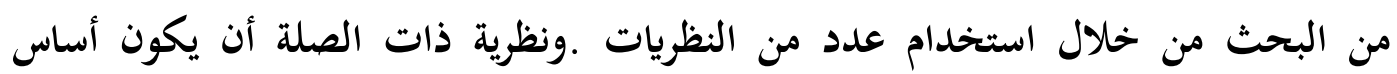

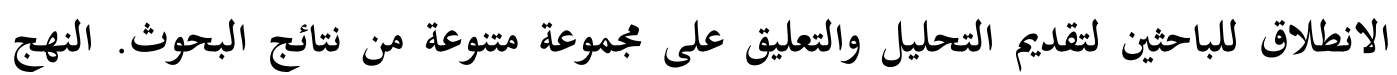
المتبع في هذه الدراسة هو المنهج النفسي، التربوي والقضائي.

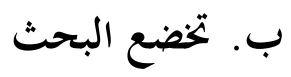

وتمدف الأنشطة البحثية أساسا في الحصول على بيانات أو معلومات غير صحيحة من الئن

مجال البحث التي يمكن تنفيذها على أساس موضوعي والبحوث المثتعلقة موضوع البحث.

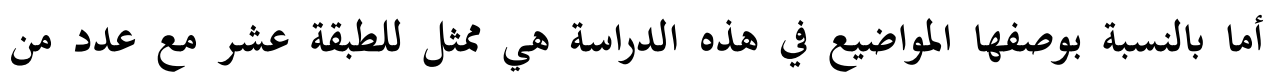

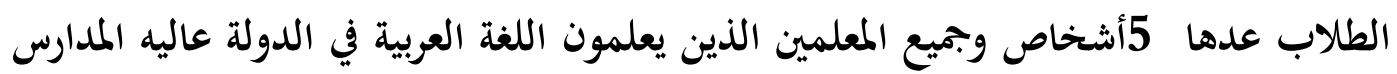

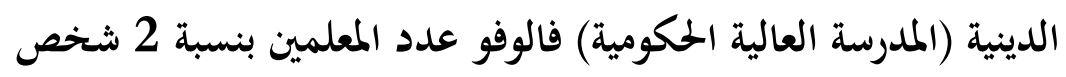
ج.مصدر البيانات في هذه الدراسة، وهناك نوعان من مصادر البيانات هي:

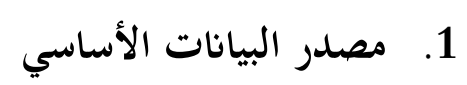

البيانات الأولية هو مصدر البيانات التي تم الحصول عليها من المصدر الأصلي،

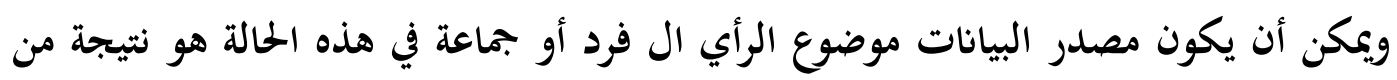
الملاحظات والمقابلات مع المعلمين والطلاب، وتصل إلى 7أشخاص.

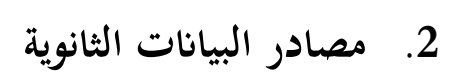

البيانات الثانوي استرجاع البيانات في شكل وثائق أن هناك والنتائج التي عثر عليها الباحث مباشرة .البيانات في شكل وثائق تتعلق الشخصية (المدرسة العالية المكومية) فالوفو. د. أساليب جمع البيانات

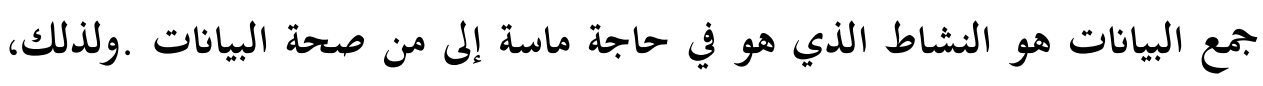

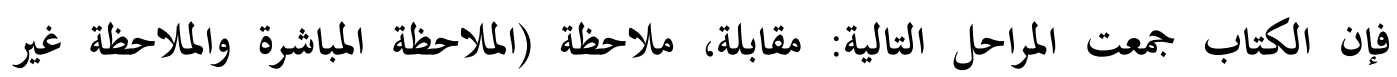
المباشرة)، وتوثيق.

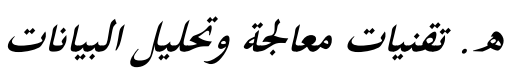
تحليل البيانات المستخدمة في هذه الدراسة منها حثى واستنتاجى ومقارنة. 


\section{نتائج البحث}

أ. نموذج الاختبارات المستخدمة في تقويم معلمي تدريس اللغة العربية في المدرسة العالية

الحكوميّة فالوفو

يتم الحصول على البيانات على مشاكل تقويم تعليم اللغة العربية في تنفيذ تقويم تعليم اللغة العربية من خلال تقنيات المقابلة، والمستمدة من مدرسي اللغة العربية وطلبة الفصل العاشر، وكلها كان عدد من المشاركين هناك 7 أشخاص .البحوث التي أجريت باستخدام أداة

مقابلة الحصول على النتائج التالية:

جدول: نوذج تقويم من قبل المعلمين اللغة العربية في المدرسة العالية الحكومية فالوفو

\begin{tabular}{|c|c|c|c|}
\hline نموذج التقويم & ءججال الدراسة & اسم المعلمين & عدد \\
\hline مرمجة مرعات النقاش & معلمة اللغة العربية & اندرمي, س أ غ. & .1 \\
\hline إعطاء العنداء الواجبات المنزلية أو & معلم اللغة العربية & لاحودين س.ف إ!. , م فد إ & .2 \\
\hline
\end{tabular}

المصدر :مقابلة مدرسى اللغة العربية في المدارس العالية الحكومية فالوفو

واستنادا إلى الجمدول أعلاه أن نموذج تقويم المعلمين في تقويم الطلاب والمعلمينين في المدارس الدينية عاليه فالوفو بلد لديه طريقة مختلفة .ليس فقط أغا تستخدم استمارات التقويم ولكن كل فهاية المناقشة تم اختبار الطلاب مرة أخرى لتحديد إلى أي مدى مستوى قدرته على فهم الموضوع تعليموه ـالمعلمينين في المدارس الدينية البلاد عاليه إعطاء المهام باستخدام اختبار الشفوي ووصف اختبار أو عادة يشار إلى اختبارات ذاتية كما ـويمكن مباشرة ذلك يتضح من الجلدول أدناه ط.

جدول: نموذج من نموذج التقويم من قبل معلمي اللغة العربية في المدرسة الدينية العالية فالوفو يمكن وصفها على النحو التالي:

\begin{tabular}{|c|c|c|c|c|}
\hline اختبارات موضوعية & الاختبارات الذاتية & اختبار شفوي & الدراسة & اسم الملدرس \\
\hline لم لم يتم & وصف /مقال & اختبار شفوي & لغة العربية & اندرمي \\
\hline لم يتم & وصف /مقال & وصف /مقال & لغة العربية & الاحودين \\
\hline
\end{tabular}


\begin{tabular}{|l|l|l|l|l|}
\hline & & & \\
\hline
\end{tabular}

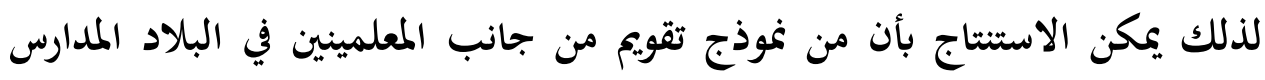

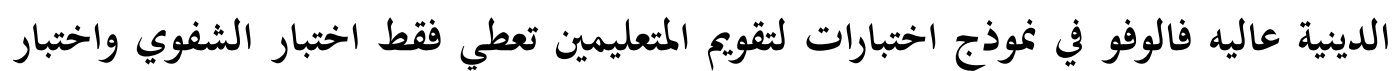

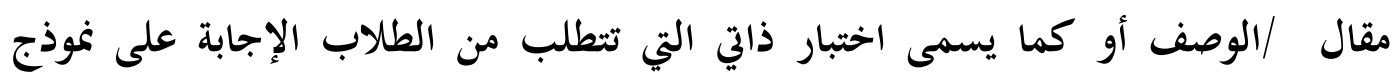

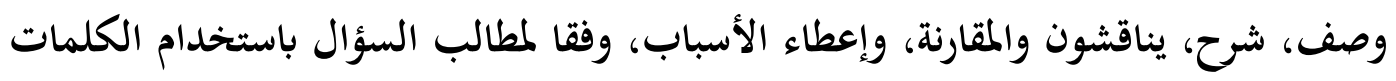

واللغة نفسها.

بينما نادرا ما يعطى اختبار موضوعي للطلاب لأن المعلمين يعتقد أن هذا الاختبار غير

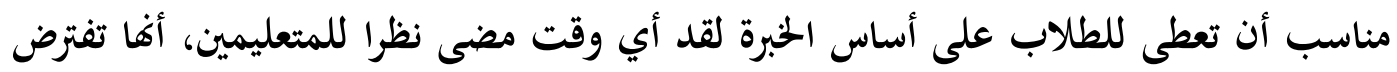

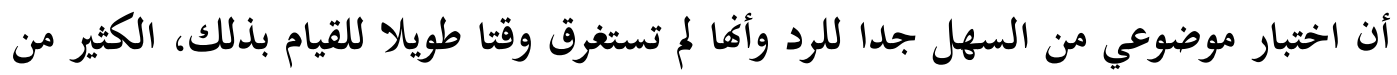

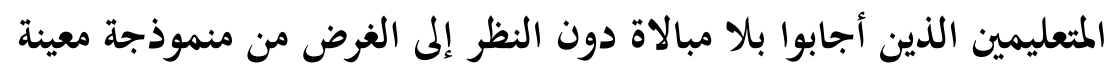
وبناء على البيان الموجود الطلاب يمكن أن تمثل اثنين من أصدقائه في الفئة التي أساسا

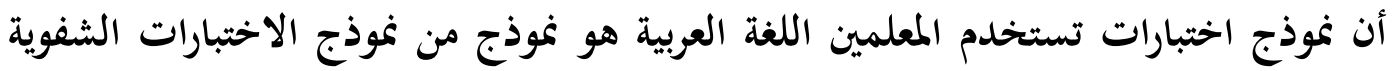

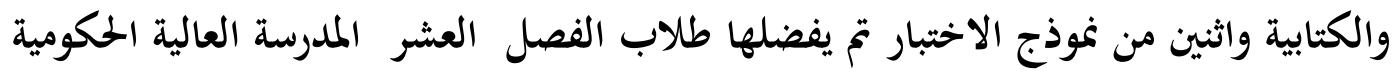
فالوفو. ب. نموذج القياس وتقييم المستخدمة في البلاد معلمي اللغة العربية المدارس الدينية عاليه فالوفو

تقويم وتفسير نتائج القياس تحقيق مخرجات التعليم هو وسيلة للحصول على معلومات

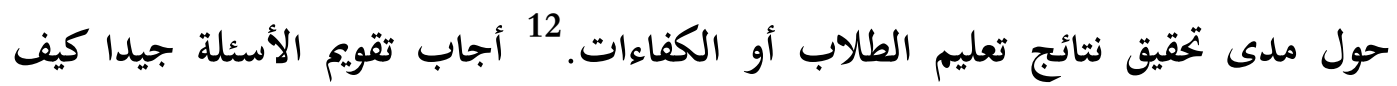

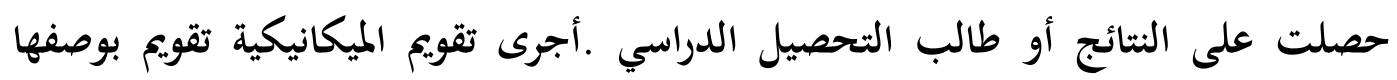

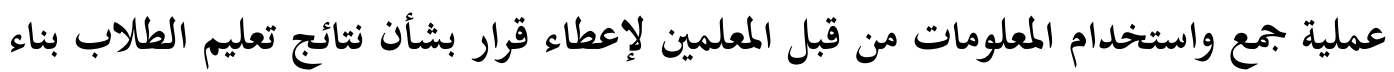

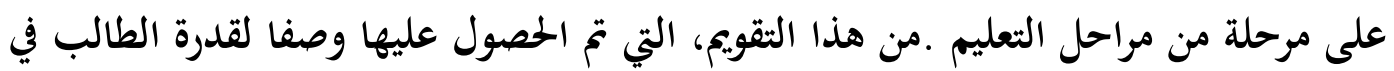

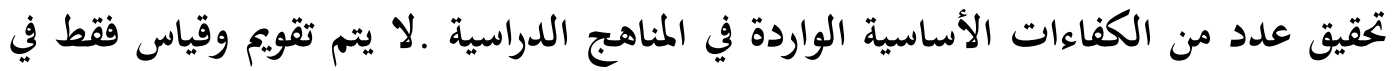

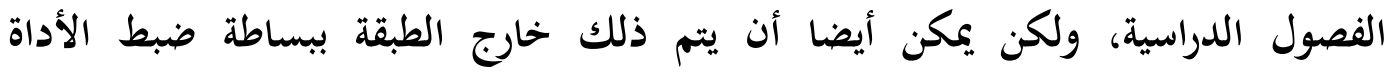
المستخدمة لتقويم الطلاب.

${ }^{12}$ Dewi Sukmara, Implementasi Life Skill dalam KTSP, (Bandung; Mughni Sejahtera, 2007), h. 161. 


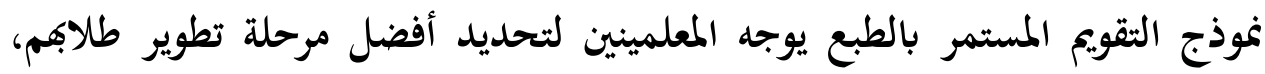

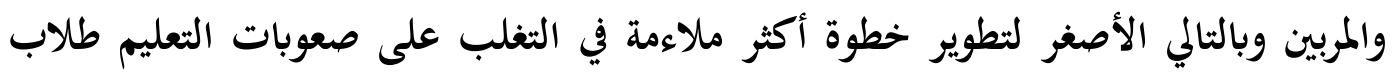

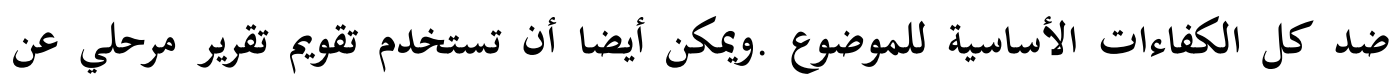
إعداد نتائج تعليم الطلبة وتحسين عملية التعليم.

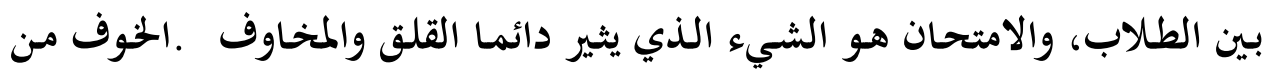

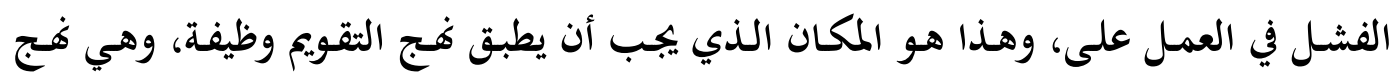

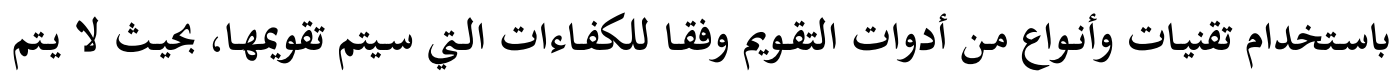

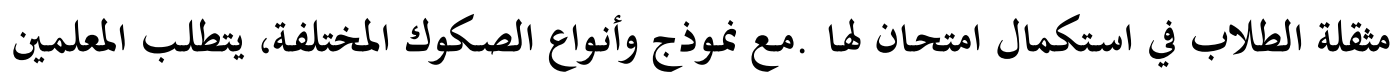

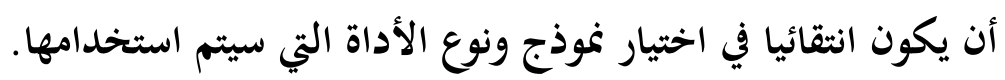

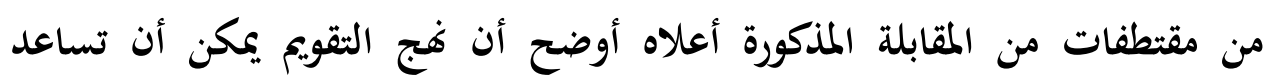

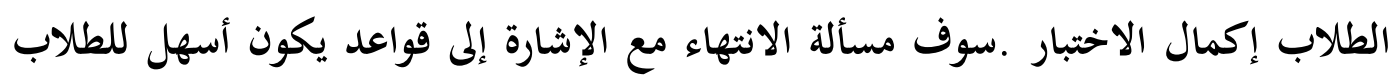

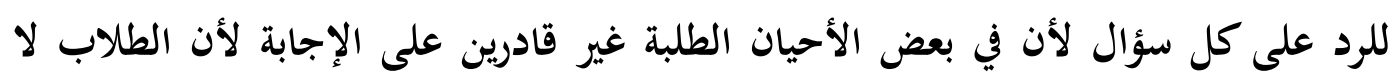

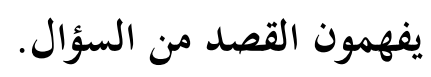
وينبغي أن يكون تقويم تقويم شامل، وهي تحقيق الكفاءة ويشمل معيار الكفاءة

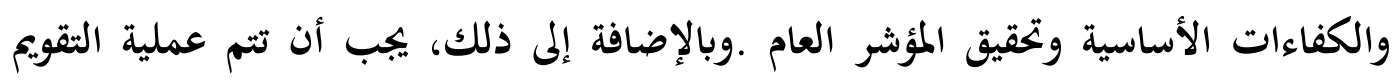

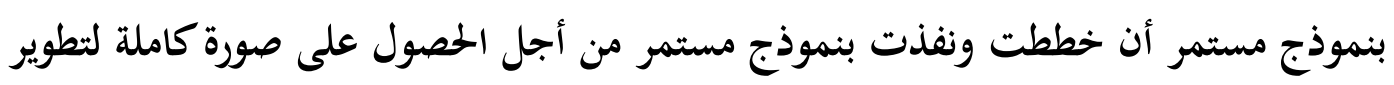
مخرجات تعليم الطلاب.

يصف تقويم آلية التقويم التي تطبقها المدارس التي تطبق على جميع الطبقات .وأكد

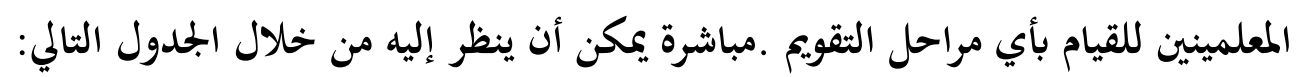

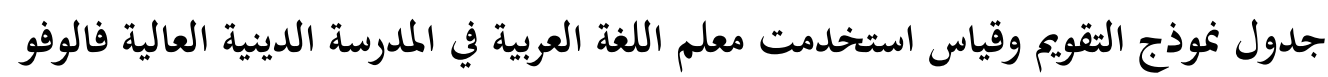

\begin{tabular}{|c|c|c|c|c|}
\hline |تقويم تنفيذ & نموذج التقويم & مجال الدراسة & اسم المعلمين & رقم \\
\hline |لاختباراتاليو مية & \multirow[t]{4}{*}{ اختبارات ذاتية } & \multirow[t]{4}{*}{ لغة العربية } & \multirow[t]{4}{*}{ اندرمي, س أ غ. } & \multirow{4}{*}{.1} \\
\hline الاختبارات النصفية & & & & \\
\hline زيادة التنية في الدرجة & & & & \\
\hline تثنية الأخ التعليم & & & & \\
\hline |لاختباراتاليومية & \multirow[t]{2}{*}{ اختبارات ذاتية } & \multirow[t]{2}{*}{ لغة العربية } & الاحودين س.ف & \\
\hline الاختبارات النصفية & & & إ..، م ف د إ & \\
\hline
\end{tabular}




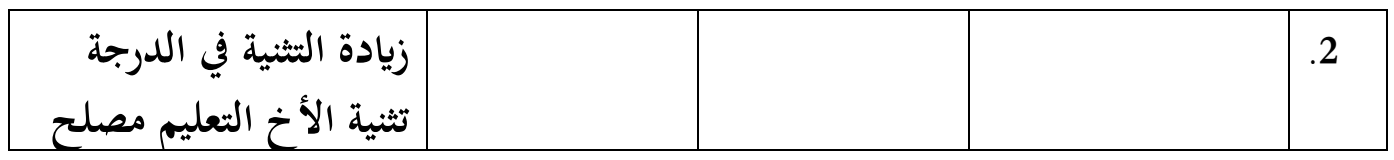

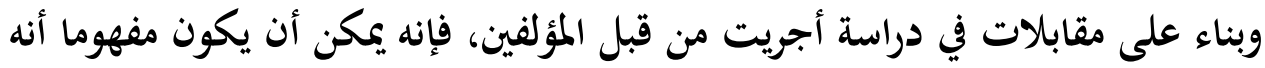

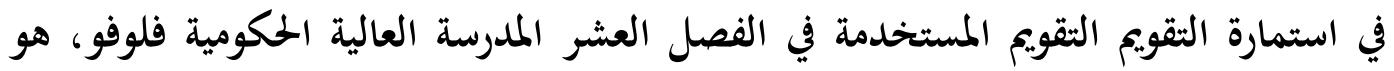

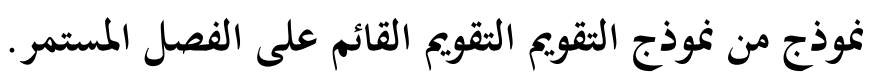

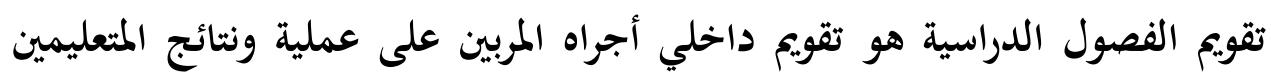

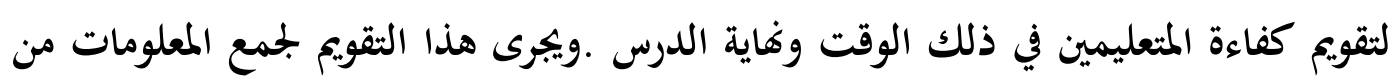

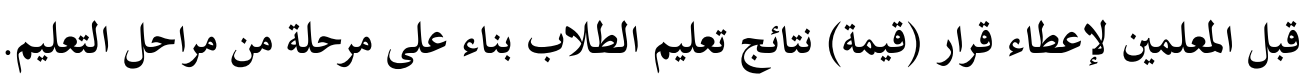

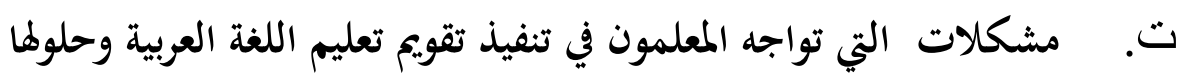

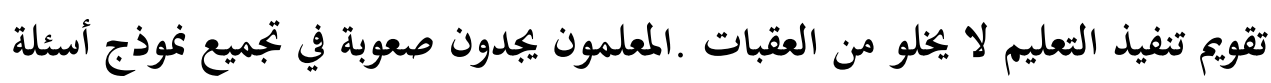

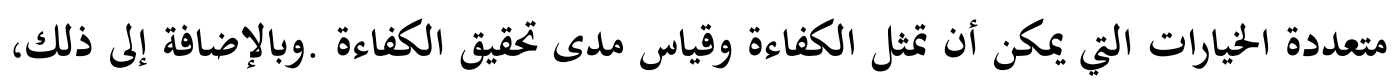

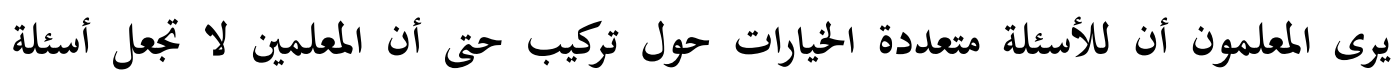

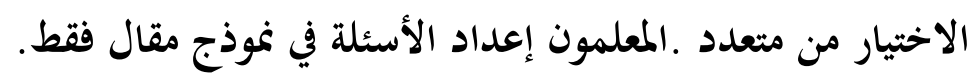

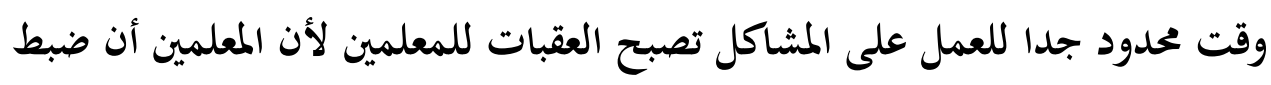

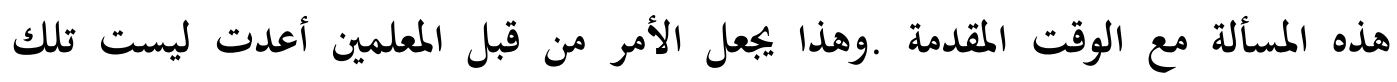

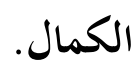

وثمة منموذجاة أخرى يواجهها المعلمون هي تحقيق معايير اكتمال الحد الأدلن (معايير اكتمال الحد الأدلن) من قبل المتعلين .عندما تقرر أن كبير المهندسين لتعليم العربية

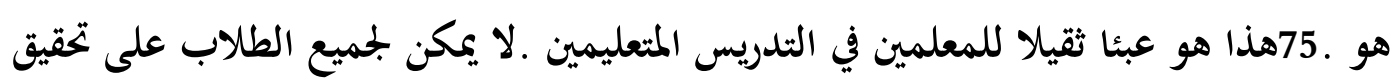

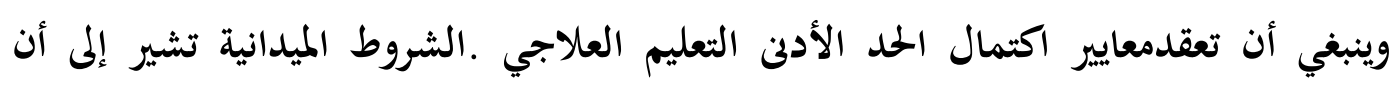
العلاجية لم تفعل من خلال تنفيذ التعليم ولكن فقط إعطاء مهام وتوجيهات لتحسين قيمتها. يتم إعطاء الحل مؤلف للتغلب على الصعوبات في تنفيذ تقويم المعلمينين تدريس اللغة العربية في المدرسة العالية الحكومية فالوفوغير:

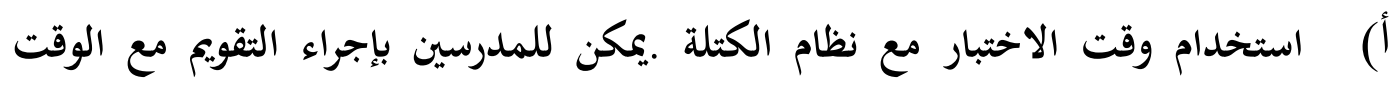

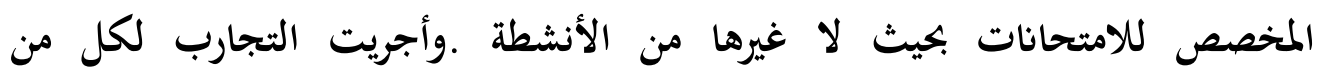


الكفاءات من اليوم .وبالتالي الطلاب لا تكون قصيرة من الوقت للعمل على المشاكل،

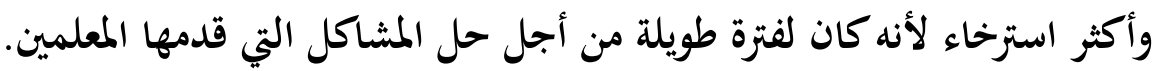

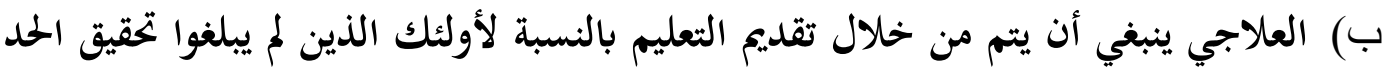

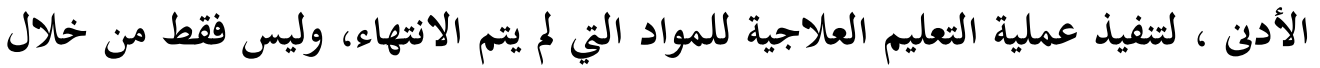
إعطاء مهمة وصفتها للتو يجب إرجاع المواد التي تم تدريسها.

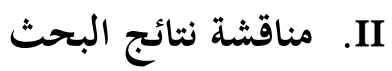
استخدام استمارة تقويم أكثر من واحد لكل الكفاءة .المعلمينين بالإضافة إلى استخدام نموذج الحطية والشفوية من التقويم، وأيضا مراقبة استعداد وصدق المتعليمين في العمل على كل

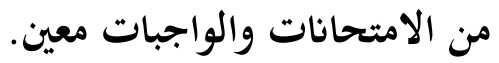

العمل الذي قام به الطلاب لا قيمة وتصبح واحدة من المكونات في التقويم النهائي من

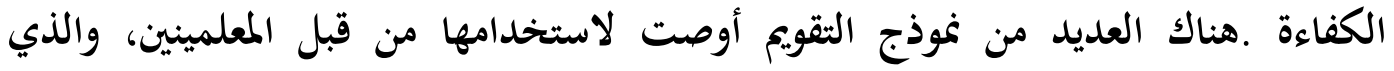
يتضمن تقويما للأداء، والموقف، والكتابة، ومشروع والمنتجات ومحفظة والتقويم الذاتي ـبينما في الحقل الجديد هناك نوعان من التقنيات المستخدمة من قبل المعلمينين هو الاختبارات الذاتية والتقويم عن طريق الفم، يجب أن المعلمينين لا يقتصر على الطريقتين كانت تستخدم في السابق .يتعين على المعلمينين استخدام مجموعة متنوعة من التقنيات في تعليم اللغة العربية وفقا

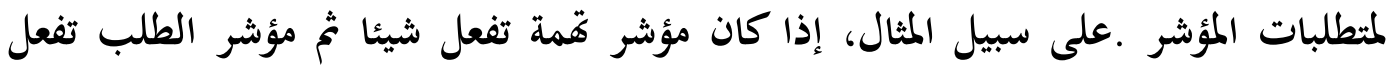
شيئا، بل هو تقنيات تقويم الأداء، وإذا كانت مطالب المؤشر هو فهم مفهوم، بل هو تقنيات تقويم مكتوب.

إعداد الاختبار الذي قام به المعلمين .المملمينون بإعداد اختبار أداة للحصول على نتائج التعليم من الطلاب .وعادة ما يتم اختبار بعد الانتهاء من التوصل إلى الكفاءات الأساسية .

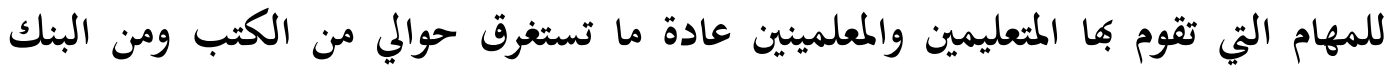

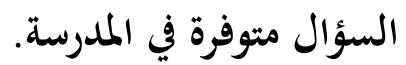
العقبات التي تواجه المعلمينين هي في معظمها التقنية .الوقت توفير أقل من ذلك عن نوعية

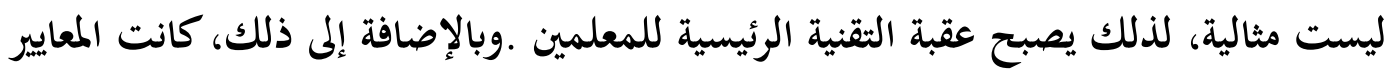

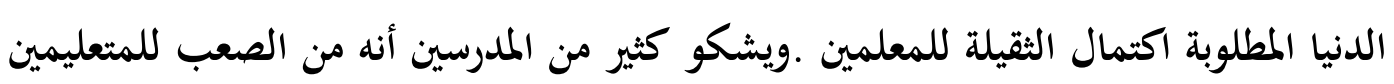
لتحقيق الحد الأدلن من معايير اكتمال تحقيق الحد الأدني 75. 
الحل نظرالعربة الباحث المعلمين لحلق نظام الجدول الزمني كتلة .وتعتبر هذه النظم لتكون قادرة على التغلب على نقص الوقت للعمل على المشاكل، وحتى نوعية الأسئلة من قبل

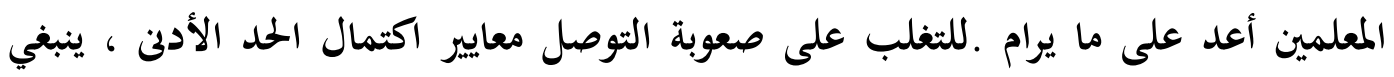

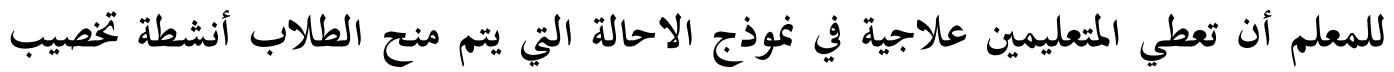

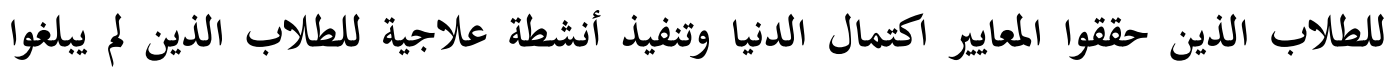
المعايير اكتمال تحقيق الحد الأدلن. الخلاصة

1. نموذج الاختبارات المستخدمة تقويم تعليم اللغة العربية في المدرسة العالية الحكومية فالوفو

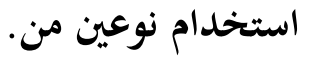

2. موذج القياس والتقويم المستخدمة في مدرس اللغة العربية الممدرسة العالية الحكومية فالوفو

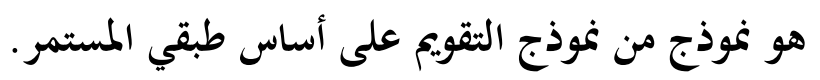

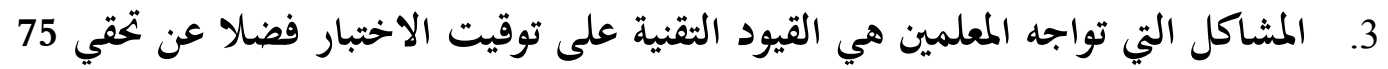
أن يشعر الثقيلة لبعض المتعليمين .قدمت حلول هو استخدام نظام جدولة كتلة بحيث

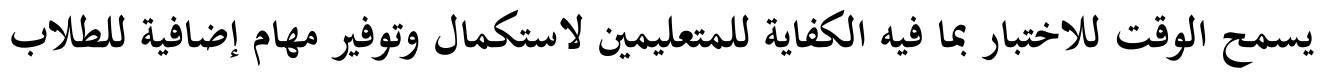

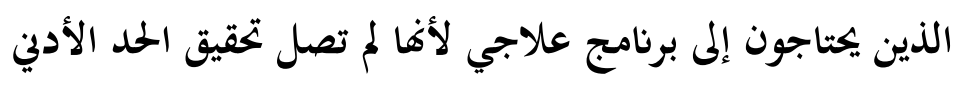

Arifin, Zaenal. Evaluasi Pembelajaran. Bandung; Remaja Rosdakarya, 2009.

Muhajir, As'Aril. Ilmu Pendidikan Perpektif Kontekstual. Cet, 1; Jogjalarta: ArRuzz Media, 2011.

Mujib, Fathul. Rekontruksi Pendidikan Bahasa Arab dari Pendekatan Konvensional ke Integrative Humanis. Yogyakarta: Bintang: Pustaka Abadi 2010.

Mulyasa, E. Standar Kompotensi Sertifikasi Guru. Bandung: Remaja Rosdakarya 2007.

Purwanto, Ngalim. Prinsip-Prinsip dan Teknik Evaluasi Pengajaran. Bandung: Remaja Rosdakarya, 2006.

Seputar pendidikan 003.blogspot.com/2010/06/Pentingnya Evaluasi Pembelajaran.html 09 september 2014.

Sudijono, Anas. Pengantar Evaluasi Pendidikan. Cet VII Jakarta: Raja Grafindo Persada 2009.

Sukmara, Dewi. Implementasi Life Skill dalam KTSP. Bandung; Mughni Sejahtera, 2007.

Syah, Muhibbin. Psikologi Pendidikan dalam Pendekatan Baru. Cet.XIII; Bandung: Remaja Rosdakarya, 2007. 